\title{
Cervical spondylotic myelopathy in the young adult: A review of the literature and clinical diagnostic criteria in an uncommon demographic
}

\author{
Peter S Amenta, MD \\ Department of Neurological Surgery, Thomas Jefferson University \\ George M. Ghobrial, MD \\ Thomas Jefferson University \\ Kelly Krespan \\ Thomas Jefferson University \\ Phi Nguyen \\ feffersen Medicaddfilibnaf works at: https://jdc.jefferson.edu/neurosurgeryfp

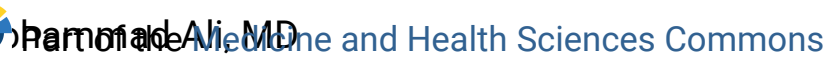 \\ Theras is feferso Uwiversitw access to this document benefits you
}

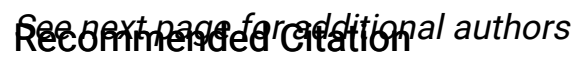

Amenta, MD, Peter S; Ghobrial, MD, George M.; Krespan, Kelly; Nguyen, Phi; Ali, MD, Mohammad; and Harrop, MD, James, "Cervical spondylotic myelopathy in the young adult: A review of the literature and clinical diagnostic criteria in an uncommon demographic" (2014). Department of Neurosurgery Faculty Papers. Paper 55.

https://jdc.jefferson.edu/neurosurgeryfp/55

This Article is brought to you for free and open access by the Jefferson Digital Commons. The Jefferson Digital Commons is a service of Thomas Jefferson University's Center for Teaching and Learning (CTL). The Commons is a showcase for Jefferson books and journals, peer-reviewed scholarly publications, unique historical collections from the University archives, and teaching tools. The Jefferson Digital Commons allows researchers and interested readers anywhere in the world to learn about and keep up to date with Jefferson scholarship. This article has been accepted for inclusion in Department of Neurosurgery Faculty Papers by an authorized administrator of the Jefferson Digital Commons. For more information, please contact: JeffersonDigitalCommons@jefferson.edu. 


\section{Authors}

Peter S Amenta, MD; George M. Ghobrial, MD; Kelly Krespan; Phi Nguyen; Mohammad Ali, MD; and James Harrop, MD 


\title{
As submitted to:
}

\section{Clinical Neurology and Neurosurgery}

\section{And later published as:}

Cervical spondylotic myelopathy in the young adult: A review of the literature and clinical diagnostic criteria in an uncommon demographic

Volume 120, May 2014, pp. 68-72

DOI: 10.1016/j.clineuro.2014.02.019

\author{
Peter S. Amenta, M.D. ${ }^{1}$ \\ George M. Ghobrial, M.D. ${ }^{1}$ \\ Kelly Krespan ${ }^{1}$ \\ Phi Nguyen $^{1}$ \\ Muhammad Ali, M.D. ${ }^{1}$ \\ James S. Harrop, M.D. ${ }^{1}$
}

\section{Thomas Jefferson University Hospital, Philadelphia, PA 19107}

Corresponding Author:

James S. Harrop, M.D.

Associate Professor

Department of Neurological Surgery

Thomas Jefferson University Hospital

Philadelphia, PA 19107

(W) 215-955-7000

(F) 215-503-9170

james.harrop@jefferson.edu

Key Words: cervical spondylotic myelopathy; diagnostic criteria; gait disturbance; spasticity

Running Head: "Cervical spondylotic myelopathy: A review of the literature"

No financial or material support was given for the preparation of this manuscript. 
No portion of this manuscript has been presented previously.

\begin{abstract}
Background Cervical spondylotic myelopathy (CSM) is typically encountered in the elderly population. Significant inconsistencies currently exist regarding the definition of the disorder, the true incidence of CSM in younger populations, and the established diagnostic criteria.
\end{abstract}

Objective To highlight the lack of standardization in the definition and diagnosis of CSM.

Methods A PubMed literature search was conducted spanning the years 2001 to 2011. The search was limited by the following terms: 1) English language, 2) Adults (19-44 years old), and 3) "cervical spondylotic myelopathy." Each article was reviewed to determine if the presence of the definition of CSM existed in the article. The clinical characteristics used to make the diagnosis of CSM were recorded for each article. Cochran's Q statistic was used to determine whether some clinical characteristics were more frequently used than others.

Results 93 papers were reviewed in detail and 16 case reports, reviews, and articles concerning less than three patients were excluded, resulting in 77 articles in the final analysis. The most common clinical definitions were gait disturbance (22/77 articles (28.6\%)), upper limb paresthesias or sensory disturbance (21/77 (27.3\%)), and clumsy hands (15/77 (19.5\%)). Hyperreflexia, spasticity, and pathologically increased reflexes were identified as diagnostic criteria in a minority of patients.

Conclusion The literature employs a wide range of neurologic signs and symptoms to make the diagnosis of CSM, with a majority of studies failing to rely on strict diagnostic criteria. The clinician should not discount CSM as an explanation for the aforementioned findings, as it is well-reported in the literature among the ages 18-44. 
Key Words: cervical spondylotic myelopathy; diagnostic criteria; gait disturbance; spasticity Introduction

Cervical spondylotic myelopathy (CSM), the most common disorder of the spinal cord in persons older than 55 years of age, remains a challenging pathology to manage in modern neurosurgical practice.[1] As the mean age of the population continues to rise, it can be expected that an increasingly frequent number of patients will present with the signs and symptoms of CSM. However, among patients with CSM, there is considerable variability in both the clinical presentation and imaging findings(Figure 1-4).[2] The temporal evolution of symptoms covers a wide range, spanning from acute to chronic progression and neurologic deterioration.[3-5], the optimal management strategy must be tailored to each individual patient and multiple surgical approaches are routinely utilized.[6-9] Despite the high frequency with which CSM is encountered in clinical practice, the diagnostic criteria continues to suffer from a significant lack of uniformity.

The diagnosis of CSM is primarily based on the clinical signs found on physical examination and is supported by imaging findings of cervical spondylosis with cord compression.[2] Numerous authors have addressed the defining clinical characteristics and diagnostic criteria, however, a careful analysis of the literature reveals multiple inconsistencies. The underlying discrepancies are multifactorial in nature, stemming from the complexity of the disease and the vast number of treatment options currently available. Additionally, the existing literature emanates from diverse specialties, including, neurology, neurosurgery, internal medicine, and rehabilitation medicine. Practitioners from different specialties encounter patients of varying acuity of symptom onset, thereby contributing to the multiple approaches to 
treatment. As a result, the comparison of data across studies, such as, indications for surgery, complications, and treatment efficacy is of limited utility.

Utilizing the PubMed search engine, the literature over the last ten years $(2001-2011)$ pertaining to the clinical presentation, diagnosis, and surgical management of CSM were reviewed. Specifically, articles were reviewed to determine if CSM was explicitly defined, to pin point the diagnosticcriteria used, and to identify discrepancies and inconsistencies between manuscripts. Additionally, we also present a review of the presenting findings in the literature of younger patient populations affected with CSM (ages 19-44).

\section{Methods}

Using the PubMed search engine, a search was conducted spanning the years 2001 to 2011. The search specifically focused on the following limiting terms: 1) English language, 2) Adults (19-44 years old), and 3) "cervical spondylotic myelopathy." Each article was individually reviewed and analyzed to determine if the authors explicitly defined CSM within the manuscript. The clinical characteristics used to make the diagnosis of CSM were recorded for each article as follows: gait disturbance, lack of coordination, clumsy hands, paresis, spasticity, hyperreflexia, hyporeflexia, sensory disturbance, pattern of weakness, Lhermitte's sign, Romberg's sign, Hoffman's sign, Babinski's sign, and bowel or bladder dysfunction.

Cochran's Q statistic was used to determine whether some clinical characteristics were more frequently used than others. Cochran's test allows analysis of data where the same item occurs in more than one category. A critical range was calculated to indicate which characteristics were selected at significant rates.[10]

\section{Results}


93 articles meeting the search criteria were identified. 16 case reports, reviews, and articles concerning less than three patients were excluded, resulting in the inclusion of 77 articles in the present study. The breakdown of the signs and symptoms are presented in Table 1 (Table 1). Cochran's $Q$ statistic indicated that the rates were significantly different, with a critical range of $16.37 \%$.

Gait disturbance, cited in $22(28.57 \%)$ of the papers reviewed, was the most common sign or symptom found in patients diagnosed with CSM. Reported in 21 (27.27\%) of the papers, loss of sensation in the upper extremities was the second most common finding. The critical range of the Cochran Q test was $16.37 \%$. Gait disturbances were therefore significantly more frequently used in CSM diagnoses than lower limb weakness $(28.57 \%-11.69 \%>16.37 \%)$ or any of the less frequently used criteria. Similarly, upper limb paresthesia or sensory disturbance was significantly different from lower-limb hyperreflexia or any less common characteristic $(27.27 \%-10.39 \%>16.37 \%)$.

Upper extremity spasticity and hyperreflexia were identified as diagnostic criteria in $15.58 \%$ and $14.29 \%$ of papers, respectively. Lower extremity spasticity and hyperreflexia, which appeared in $8(10.39 \%)$ and $7(9.09 \%)$ papers, respectively, were not described as frequently as identical findings in the upper extremities. Pathologically increased reflexes were noted in a minority of studies: Hoffman's sign (6.49\%) and Babinski's sign (5.19\%). Eleven different signs or symptoms were found to be reported as diagnostic criteria with a frequency between $1.30 \%$ and $9.09 \%$.

\section{Discussion}

CSM remains a poorly defined clinical entity due, in large part, to the widely varying diagnostic criteria employed by practitioners. As a result, it is difficult to make meaningful 
comparisons between data sets, particularly when attempting to define indications for surgery, outcomes, and improvement or decline in functional status. As demonstrated in this review, the diagnosis of CSM should not be regarded as solely a disease of the elderly. Numerous studies are cited in the literature, as in our search which found 7510 patients across 77 papers. The present study also highlights the inconsistencies within the existing literature and identifies signs and symptoms commonly attributed to CSM.

\section{Long-tract Signs}

Long tract signs, such as, upper and lower extremity spasticity and hyperreflexia, serve as evidence of a disease process arising in the upper motor neurons of the corticospinal, spinothalamic, and posterior column tracts. In patients with CSM, degenerative changes in the cervical spine result in compression of the spinal cord and resultant upper motor neuron dysfunction. As a result, long-tract signs are generally regarded as hallmarks of CSM.[11-14] In the present study, however, only a relatively small number of articles cited these findings. Signs consistent with pathologically increased reflexes, such as Hoffman's (5.38\%) and Babinski's (4.30\%) signs, were also noted in only a small percentage of studies.

The relatively low frequency with which these findings were included among the diagnostic criteria was perhaps the most striking evidence of the poorly defined parameters. Most often, evidence of CSM on MRI was the major inclusion criteria, in place of long tract findings on examination. Still, findings on MRI were not standardized across studies, with broadly generalized spondylosis and cord compression being the most routinely found description. Other potential explanations for the disparities, include, improper diagnosis of a subset of patients or the inclusion of patients with varying degrees of disease progression under an all-encompassing term of CSM. However, we chose a younger age group to limit the 
variability in disease progression than occurs in later adulthood. In either case, the comparison of data between studies is rendered inadequate.

The differential diagnosis for a patient presenting with myelopathy is broad and includes, inflammatory, infectious, vascular, traumatic, degenerative, toxic/metabolic, and neoplastic processes.[15] Few papers in our series attempted to pursue diagnostic testing beyond imaging to establish a diagnosis of CSM, thereby raising the question of misdiagnosis. When evaluated in the context of the widely varying diagnostic criteria described above, the diagnostic accuracy is considered even more suspect. Patients with true CSM presenting without hyperreflexia or spasticity on exam are most likely presenting earlier in their disease course. Inclusion of these patients with those more profoundly affected skews data interpretation, as the natural history of CSM is variable and difficult to predict.[16-18]

\section{Symptoms}

Gait disturbance (28.57\%) and loss of sensation in the upper extremities (27.27\%) were the most commonly identified presenting symptoms. However, they were noted in less than a third of the articles reviewed and there was no significant difference between the frequency of their reporting and several other commonly cited neurologic findings. Additionally, eleven different signs or symptoms were found to be reported as diagnostic criteria with a frequency between $1.30 \%$ and $9.09 \%$. These results highlight the variability in diagnostic criteria between studies and the broad range of findings utilized by various authors in making the diagnosis of CSM.

Multiple scores, including, the Nurick-score, modified Japanese orthopaedic association score (mJOA score), Cooper myelopathy scale (CMS), Prolo-score, and European myelopathy score (EMS) have been developed in an attempt to standardize the diagnosis of CSM.[19-24] 
These scores are commonly referenced in the literature and are most extensively used in the research setting. They are rarely employed in clinical practice and their utility is limited by the fact that they are largely based on the ability of patients to participate in activities of daily living.[2] As a result, they do not reflect objective criteria on neurologic examination, results are inherently "user" dependent, and meaningful interpretation across studies is limited. In our analysis, we found the majority of papers to report the JOA score, which is calculated from answers provided by patients on a questionnaire pertaining to their neurologic function. Obviously, this scoring system relies heavily on the interpretation of symptoms by an individual patient and lacks stringent criteria when attempting to define diagnostic criteria or outcomes. Nikaido et al. highlighted these inconsistencies in a prospective analysis of 87 patients who had undergone surgical treatment of CSM.[21] The authors reported a lack of improvement in upper extremity function on JOA scores despite the fact that improved function was clearly observed on objective testing.

The present study is limited by its retrospective design and the broad spectrum of study types from which data was pooled. As mentioned above, the majority of studies did not pursue advanced diagnostic testing to establish a true diagnosis of CSM. Thus, there is significant suspicion of inclusion of patients without CSM. Also, due to the very nature and goals of the study, the inconsistencies inherent in the papers limit analysis of the data. Nevertheless, we have effectively demonstrated the need for specific standards for reporting in CSM, given its high prevalence as a surgical disease. Furthermore, the data emphasizes the need for prospective analysis of patients presenting with symptomatology consistent with CSM and highlights the shortcomings of existing patient-centered clinical scales. Recent prospective studies in the past five years have been published that specify strict radiographic criteria for defining spondylotic 
disease. However, standards should be adopted to make for accurate comparison, as these radiographic criteria vary between studies, as well as the clinical criteria.

Surgical decompression has been shown in previous studies to limit disease-progression and improve myelopathy [25-32]. However, a specific subgroup analysis comparing earlier onset CSM as defined by our age range 18-44 and their respective surgical outcomes is lacking. The authors were able to identify the frequency of this disease where possible in the literature, however, due to the lack of a common myelopathy grading scheme (JOA, mJOA, Nurick, Oswestry) and unifying age group, conclusions on surgical outcome are restricted to that of prior studies.

\section{Conclusion}

The literature demonstrates a wide range of neurologic signs and symptoms that are employed to make the diagnosis of CSM, with the majority of studies failing to employ stringent diagnostic criteria. The clinician should not discount CSM as an explanation for the aforementioned findings, as it is is well-reported in the literature among the ages 18-44.

\section{References}

1. Cooper PR. Cervical spondylotic myelopathy. Contemp Neurosurg 1997;19:1-7.

2. Tracy JA, Bartleson JD. Cervical spondylotic myelopathy. The Neurologist 2010;16:176-187.

3. Cusick JF. Pathophysiology and treatment of cervical spondylotic myelopathy. Clin Neurosurg 1989;37:661-681.

4. Vitzthum H, Dalitz K. Analysis of five specific scores for cervical spondylogenic myelopathy. European spine journal : official publication of the European Spine Society, the European Spinal Deformity Society, and the European Section of the Cervical Spine Research Society 2007;16:2096-2103.

5. Yu Y, du Boulay GH, Stevens JM, al. e. Computed tomography in cervical spondylotic myelopathy and radiculopathy: Visualization of structures, myelographic comparison, cord measurements and clinical utility. Neuroradiology 1986;28:221-236.

6. Heller JG, Edwards CC, Murakami H, Rodts GE. Laminoplasty versus laminectomy and fusion for multilevel cervical myelopathy an independent matched cohort analysis. Spine 2001;26:1330-1336.

7. Katsuhiro O, Norihiko A, Soichi K, Atsushi T, Hisanori M, Tsuneatsu T. Long-term follow-up results of anterior interbody fusion applied for cervical myelopathy due to ossification of the posterior longitudinal ligament. Spine 2001;26:488-493. 
8. Edwards CC, Heller JG, Murakami H. Corpectomy versus laminoplasty for multilevel cervical myelopathy an Independent matched-cohort analysis. Spine 2002;27:1168-1175.

9. Carol MP, Drucker TB. Cervical spondylitic myelopathies: surgical treatment. Journal of spinal disorders 1988;1:59-65.

10. Sheskin DJ. The Cochran Q Test. Handbook of parametric and nonparametric statistical procedures. Boca Raton: Chapman and Hall/ CRC 2007:1099-1116.

11. Klineberg E. Cervical spondylotic myelopathy: a review of the evidence. The Orthopedic clinics of North America 2010;41:193-202.

12. Acharya S, Srivastava A, Virmani S, Tandon R. Resolution of physical signs and recovery in severe cervical spondylotic myelopathy after cervical laminoplasty. Spine 2010;35:E1083-1087.

13. Harrop JS, Naroji S, Maltenfort M, Anderson DG, Albert T, Ratliff JK, Ponnappan RK, Rihn JA, Smith HE, Hilibrand A, Sharan AD, Vaccaro A. Cervical Myelopathy: A Clinical and Radiographic Evaluation and Correlation to Cervical Spondylotic Myelopathy. Spine 2010.

14. Harrop JS, Hanna A, Silva MT, Sharan A. Neurological manifestations of cervical spondylosis: an overview of signs, symptoms, and pathophysiology. Neurosurgery 2007;60:S14-20.

15. Bartleson JD, Deen HG. Chapter 9. Spine disorders: medical and surgical management. NY: Cambridge University Press 2009:174-175.

16. Koyanagi T, Hirabayashi K, Satomi K, Toyama Y, Fujimara Y. Predictability of operative results of cervical compression myelopathy based on preoperative computed tomographic myelography. Spine 1993;18:1958-1963.

17. Kadanka K, Mares M, Bednarik J, Smrcka V, Krbec M, Chaloupka R, Dusek L. Predictive factors for spondylotic cervical myelopathy treated conservatively or surgically. European Journal of Neurology 2005; 12:55-63.

18. Kadanka K, Bednarik J, Vohanka S, al. e. Conservative treatment vs surgery in spondylotic cervical myelopathy: prospective randomised study. European spine journal : official publication of the European Spine Society, the European Spinal Deformity Society, and the European Section of the Cervical Spine Research Society 2000;9:538-544.

19. Nurick S. The pathogenesis of the spinal cord disorder associated with cervical spondylosis. Brain 1972;95:87-100.

20. Hukuda S, Mochizuki T, Ogata $M$, al. e. Operations for cervical spondylotic myelopathy: a comparison of the results of anterior and posterior procedures. J Bone Joint Surg Br 1985;67:609-615.

21. Nikaido T, Kikuchi S, Yabuki S, Otani K, Konno S. Surgical treatment assessment using the Japanese orthopedic association cervical myelopathy evaluation questionnaire in patients with cervical myelopathy: a new outcome measure for cervical myelopathy. Spine 2009;34:2568-2572.

22. Cooper PR, Epstein F. Radical resection of intramedullary spinal cord tumors in adults: recent experience in 29 patients. J Neurosurg 1985;63:492-499.

23. Prolo DJ, Oklund SA, Butcher M. Toward uniformity in evaluating the results of lumbar spine operations: a paradigm applied to posterior lumbar interbody fusions. Spine 1986;11:601-606.

24. Herdmann J, Linzbach M, Krzan M. The European myelopathy score. In: Baucher BL, Brock M, Klinger M, editors. Advances in Neurosurgery. Berlin: Springer Verlag 1994:266-268.

25. Manzano GR, Casella G, Wang MY, Vanni S, Levi AD. A prospective, randomized trial comparing expansile cervical laminoplasty and cervical laminectomy and fusion for multilevel cervical myelopathy. Neurosurgery 2012;70:264-277.

26. Lao L, Zhong G, Li X, Qian L, Liu Z. Laminoplasty versus laminectomy for multi-level cervical spondylotic myelopathy: a systematic review of the literature. Journal of orthopaedic surgery and research 2013;8:45. 
27. Yuan W, Zhu Y, Liu X, Zhou X, Cui C. Laminoplasty versus skip laminectomy for the treatment of multilevel cervical spondylotic myelopathy: a systematic review. Archives of orthopaedic and trauma surgery 2014;134:1-7.

28. Woods BI, Hohl J, Lee J, Donaldson W, 3rd, Kang J. Laminoplasty versus laminectomy and fusion for multilevel cervical spondylotic myelopathy. Clinical orthopaedics and related research 2011;469:688695.

29. Heller JG, Edwards CC, 2nd, Murakami H, Rodts GE. Laminoplasty versus laminectomy and fusion for multilevel cervical myelopathy: an independent matched cohort analysis. Spine 2001;26:1330-1336.

30. Ghogawala Z. Commentary: Patient heterogeneity complicates efforts to compare effectiveness for anterior versus posterior surgery for cervical spondylotic myelopathy. The spine journal : official journal of the North American Spine Society 2013;13:732-733.

31. Liu T, Xu W, Cheng T, Yang HL. Anterior versus posterior surgery for multilevel cervical myelopathy, which one is better? A systematic review. European spine journal : official publication of the European Spine Society, the European Spinal Deformity Society, and the European Section of the Cervical Spine Research Society 2011;20:224-235.

32. Ghogawala Z, Coumans JV, Benzel EC, Stabile LM, Barker FG, 2nd. Ventral versus dorsal decompression for cervical spondylotic myelopathy: surgeons' assessment of eligibility for randomization in a proposed randomized controlled trial: results of a survey of the Cervical Spine Research Society. Spine 2007;32:429-436.

\section{Table Legend}

Table 1. Incidence of individual signs/ symptoms found in reviewed papers. Gait disturbance, which was identified in $28.57 \%$ of papers, was the most commonly cited sign or symptom. Eleven different signs and symptoms were reported with a frequency between 1.30 and 9.09\%. Data was analyzed by Cochran's Q test and the critical range was $16.37 \%$.

\begin{tabular}{|l|c|c|c|}
\hline \multicolumn{1}{|c|}{ Sign/ Symptom } & $\begin{array}{c}\text { Upper/ Lower Extremity } \\
\text { Involvement }\end{array}$ & $\begin{array}{c}\text { Number of } \\
\text { Papers }\end{array}$ & $\begin{array}{c}\text { Percentage of } \\
\text { Papers }\end{array}$ \\
\hline Gait disturbance & & 22 & $28.57 \%$ \\
\hline $\begin{array}{l}\text { Pattern of loss of sensation } \\
\text { (paresthesia/sensory disturbance) }\end{array}$ & UL & 21 & $27.27 \%$ \\
\hline $\begin{array}{l}\text { Clumsy hands } \\
\text { Spasticity }\end{array}$ & UL & 15 & $19.48 \%$ \\
\hline $\begin{array}{l}\text { Pattern of loss of sensation } \\
\text { paresthesia/sensory disturbance) }\end{array}$ & LL & 12 & $15.58 \%$ \\
\hline Hyperreflexia & UL & 12 & $15.58 \%$ \\
\hline Pattern of weakness & UL & 11 & $14.29 \%$ \\
\hline Pattern of weakness & LL & 9 & $14.29 \%$ \\
\hline Hyperreflexia & LL & 8 & $11.69 \%$ \\
\hline Spasticity & LL & 7 & $10.39 \%$ \\
\hline Bowel/bladder dysfunction & & 7 & $9.09 \%$ \\
\hline Lack of coordination & & 6 & $9.09 \%$ \\
\hline
\end{tabular}




\begin{tabular}{|l|c|c|c|} 
Paresis & UL & 6 & $7.79 \%$ \\
\hline Paresis & LL & 5 & $6.49 \%$ \\
\hline Hoffman's Sign & & 5 & $6.49 \%$ \\
\hline Babinski's Sign & & 4 & $5.19 \%$ \\
\hline Lhermitte's Sign & & 2 & $2.60 \%$ \\
\hline Romberg's Sign & & 2 & $2.60 \%$ \\
\hline Hyporeflexia & UL & 1 & $1.30 \%$ \\
\hline Hyporeflexia & LL & 1 & $1.30 \%$ \\
\hline
\end{tabular}

\section{Figure Legend}

Figure 1. MRI, sagittal T2-weighted imaging of the cervical spine demonstrating pronounced focal cervical stenosis between C3 and C6. Hyperintensity of the cervical spinal cord is seen, most pronounced at $\mathrm{C} 4$. 


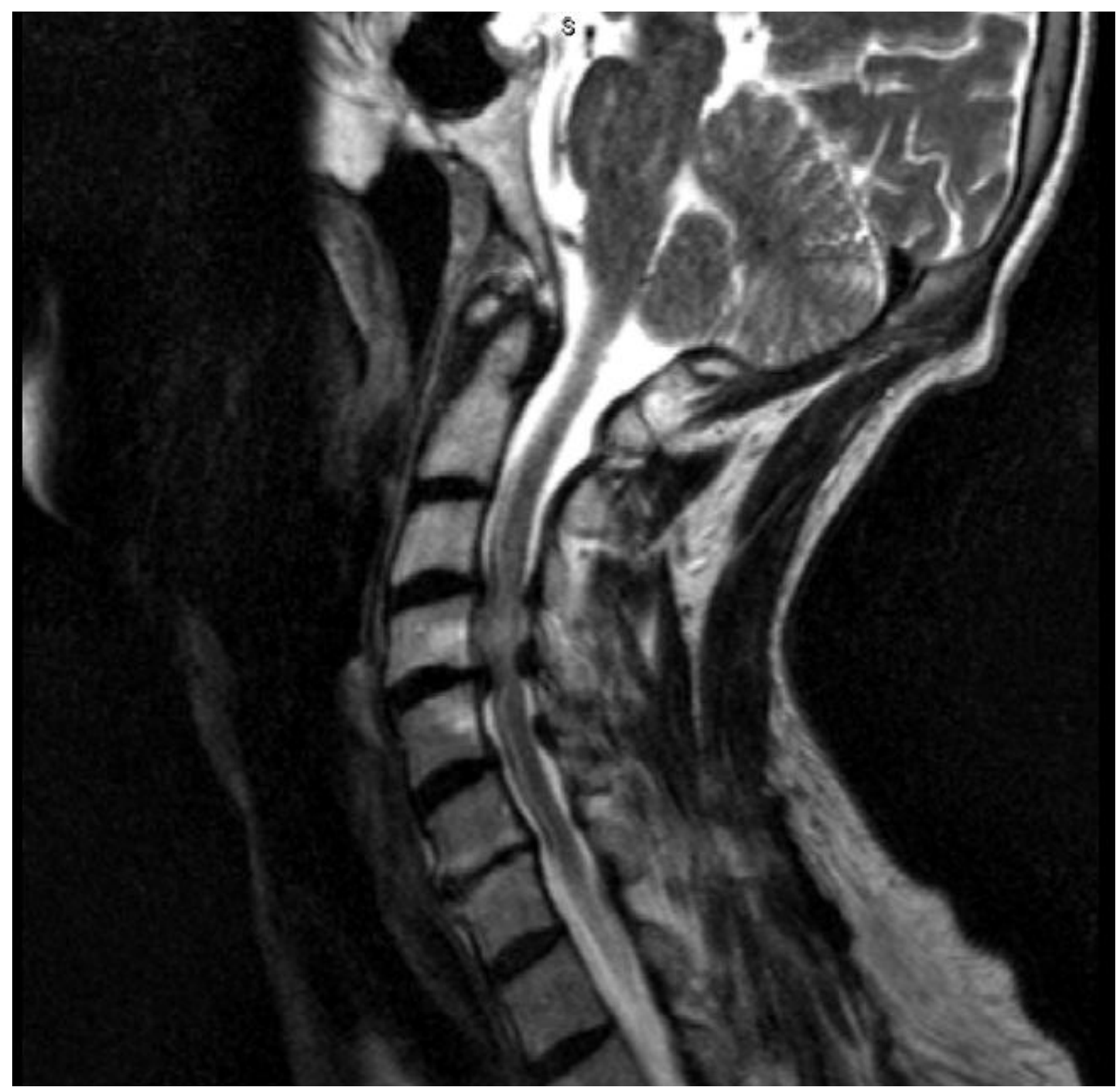

Figure 2. MRI, axial T2-weighted imaging of the cervical spine at the level of C4-C5 showing a circumferential absence of cerebrospinal fluid signal. 


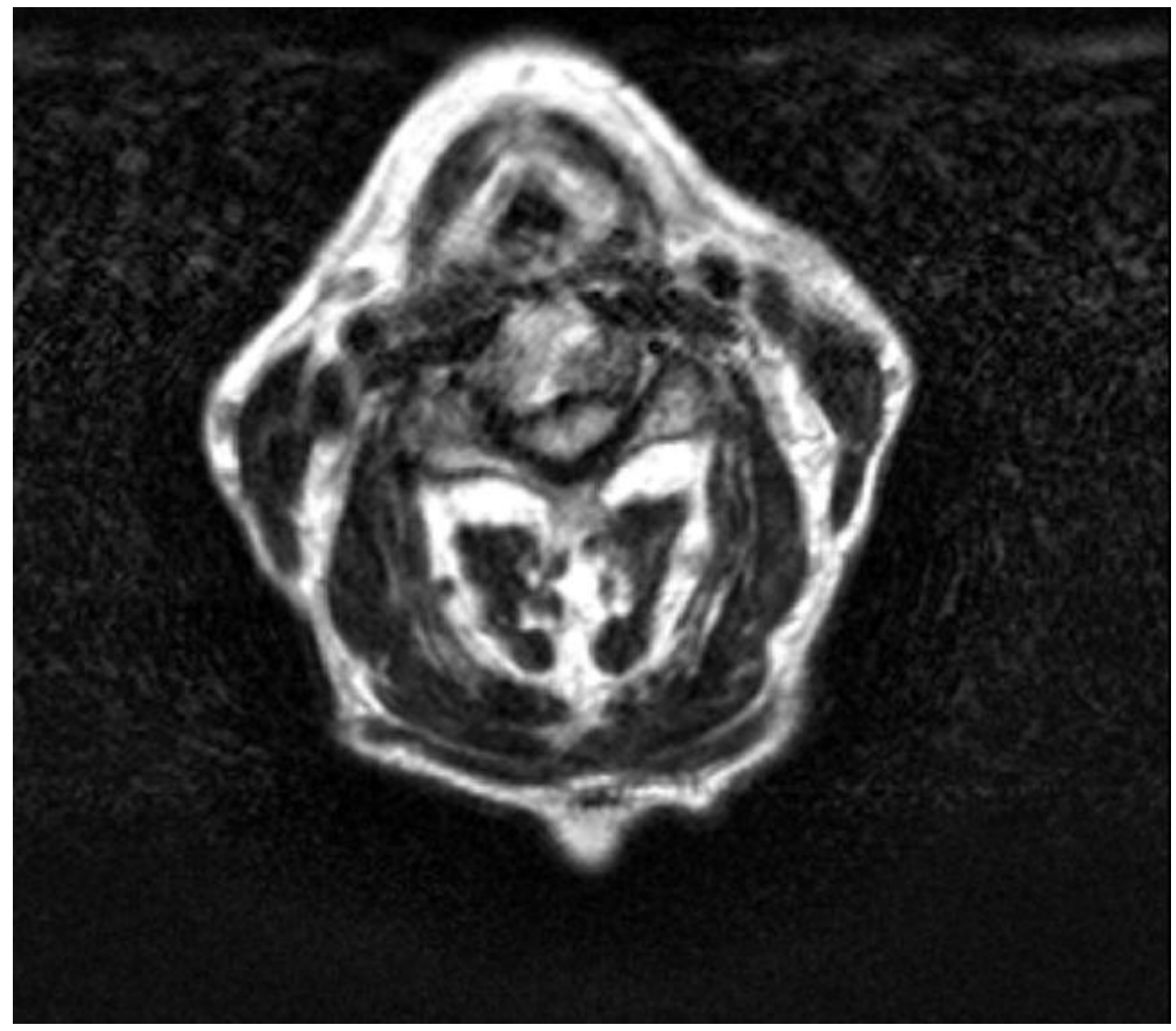

Figure 3-4.CT, sagittal and corresponding C4-C5 axial views of the cervical spine showing minimal to moderate degenerative spondylosis of the neck. 
Ghobrial 15

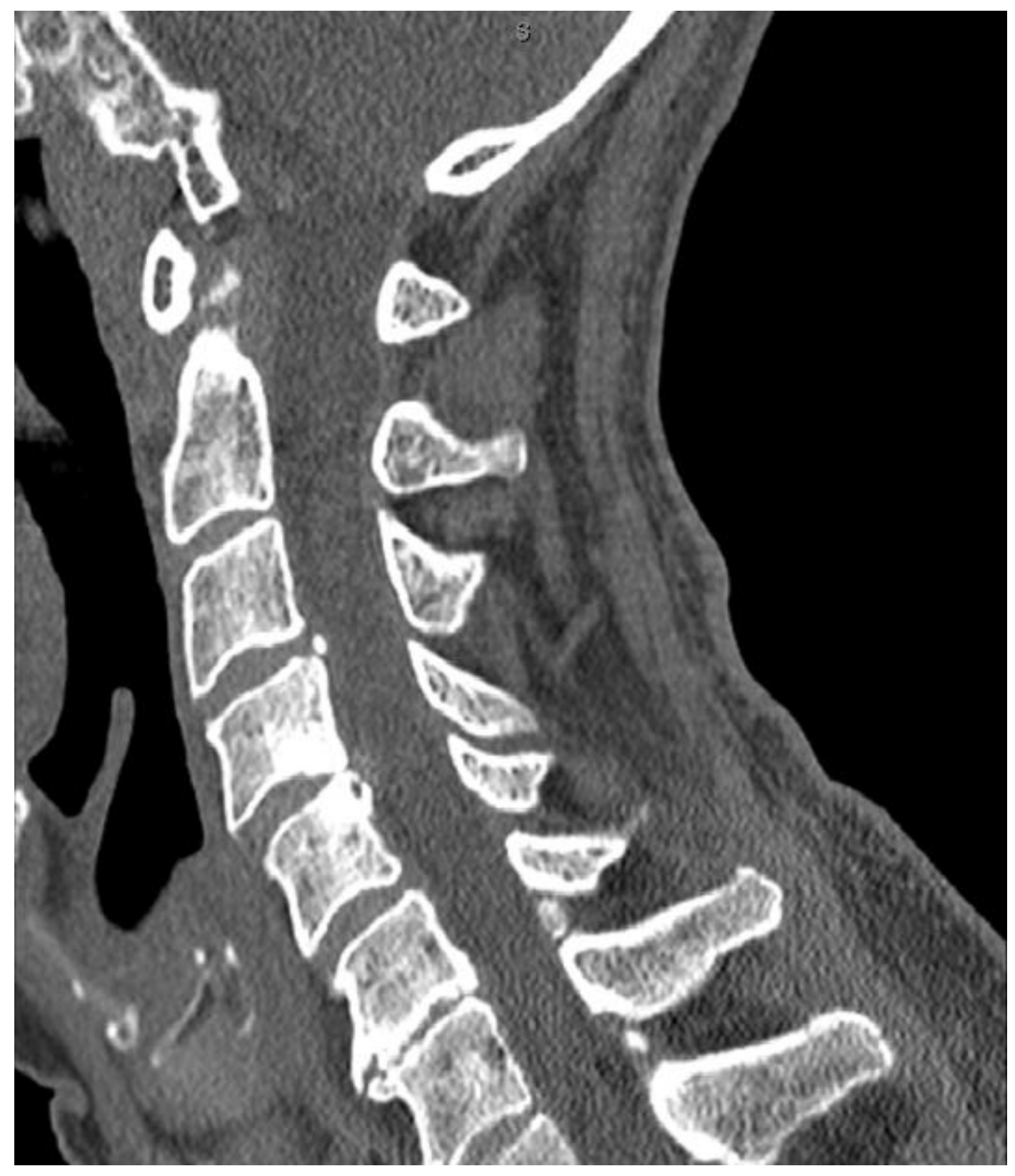


Ghobrial 16

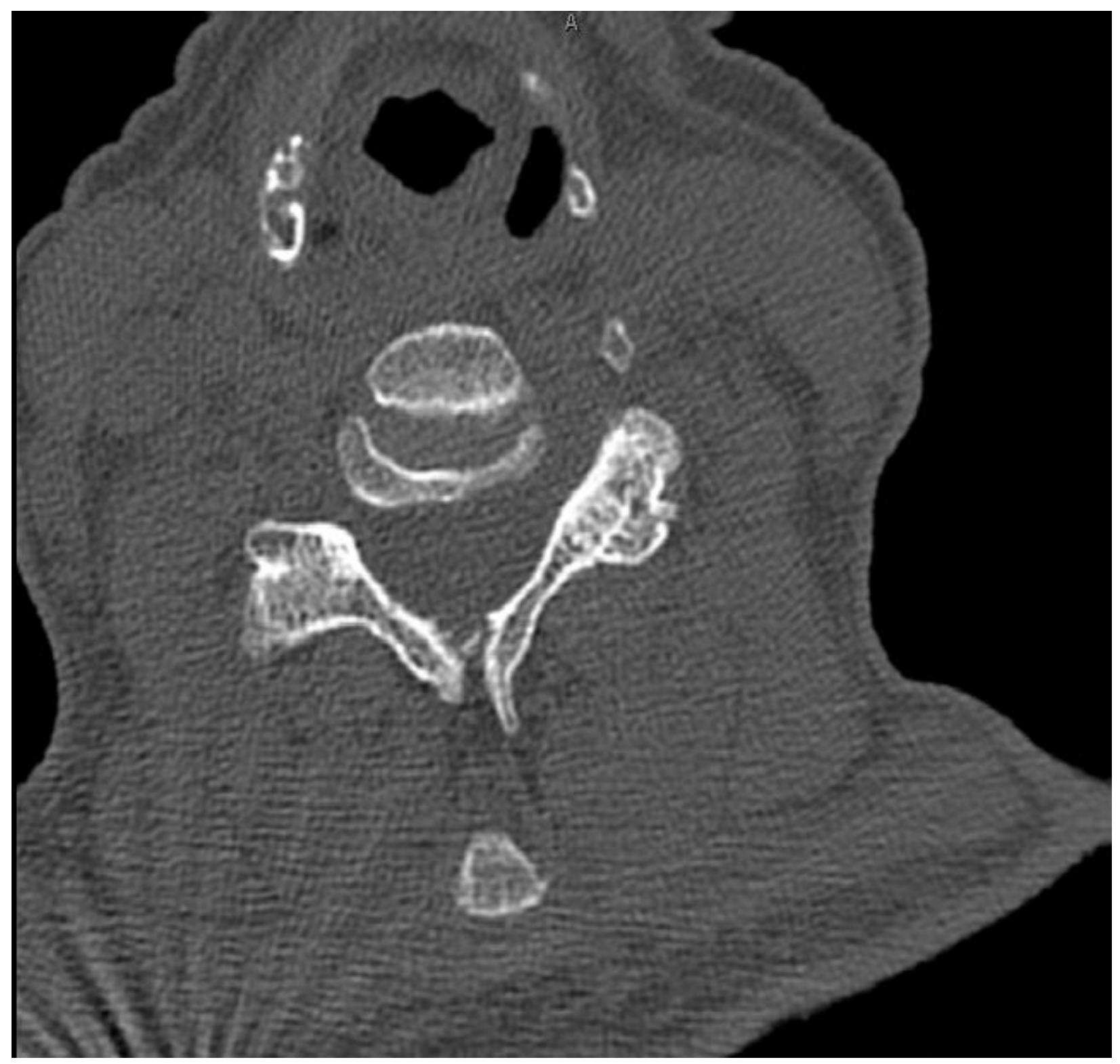

